\title{
ANALISIS KINERJA LALU LINTAS DI JALAN SEKITAR HYPERMART JL.VETERAN,PENANGGUNGAN, KLOJEN, MALANG
}

\author{
Savira Anggraeni *1, Yosef Cahyo S. P ${ }^{2}$, Sigit Winarto ${ }^{3}$. \\ ${ }^{1,2,3}$ Fakultas Teknik, Universitas Kadiri. \\ e-mail:*1aviraanggra@gmail.com, ${ }^{2}$ yosef.cs@unik-kediri.ac.id, \\ 3 sigit.winarto@unik-kediri.ac.id.
}

\begin{abstract}
This research was conducted to determine the peak traffic volume, road capacity, degree of saturation, analyze traffic performance, find out the prediction of the next 5 years, and to evaluate the traffic performance around the Hypermart shopping center that occurs in the real situation. The method used is by library research, looking for references from previous research and direct observation. The peak traffic volume is 1469 SMP / hour for the first location and 1104.4 SMP / hour for the second location. The capacity of the road section is 4699.73 SMP / hour. For the analysis of the degree of saturation of the first location of 0.31 SMP / hour and 0.23 SMP / hour in the second location. For the next 5 years prediction in that region, it is predicted to increase by $8.93 \%$ so that the volume of vehicles will rise to 2124.76 SMP / hour, and for the degree of saturation of 0.45 , which means that the traffic service in this region is included in class $C$ in 2024.
\end{abstract}

Keywords: $\quad$ Performance Analysis Of Traffic, Traffic Volume, The Degree Of Saturation, Roads

\begin{abstract}
Abstrak
Penelitian ini dilaksanakan untuk mengetahui volume puncak lalu lintas, kapasitas jalan,derajat kejenuhan, menganalisis kinerja lalu lintas, mengetahui prediksi 5 tahun ke depan serta untuk mengevaluasi kinerja lalu lintas di sekitar pusat perbelanjaan Hypermart yang terjadi disituasi rill. Metode yang digunakan adalah dengan cara studi pustaka, mencari referensi dari penelitian terdahulu serta melakukan observasi langsung. Volume puncak lalu lintas didapatkan nilai $1469 \mathrm{smp} / \mathrm{jam}$ untuk lokasi pertama dan $1104.4 \mathrm{smp} / \mathrm{jam}$ untuk lokasi kedua. Kapasitas ruas jalan sebesar $4699.73 \mathrm{smp} / \mathrm{jam}$.Untuk analisa derajat kejenuhan lokasi pertama sebesar $0.31 \mathrm{smp} / \mathrm{jam}$ dan $0.23 \mathrm{smp} / \mathrm{jam}$ pada lokasi kedua.Untuk prediksi 5 tahun kedepan pada wilayah tersebut diprediksi akan mengalami kenaikan sebesar $8.93 \%$ sehingga volume kendaraan akan naik menjadi $2124.76 \mathrm{smp} / \mathrm{jam}$, dan untuk nilai derajat kejenuhan sebesar 0.45 yang artinya pelayanan lalu lintas wilayah ini termasuk ke dalam kelas $\mathrm{C}$ pada tahun 2024.
\end{abstract}

Kata Kunci : $\quad$ Analisis Kinerja Lalu Lintas, Volume Lalu Lintas, Derajat Kejenuhan, Ruas Jalan 


\section{PENDAHULUAN}

Lalu lintas ialah sebuah perjalan bolak-balik atau pulang pergi, atau bisa dikatakan dengan perjalanan hilir mudik di jalan dari tempat satu ke tempat yang lainnya [1][2][3]. Sedangkan lalu lintas menurut Hidayah (2015) ialah gerak sebuah kendaraan yang dikendarai oleh orang diruang lalu lintas jalan [4][5].Bangkitan dan juga tarikan yang terjadi ketika tidak dipersiapkan dengan baik bagaimana cara mengatasi atau mengakomodasinya maka akan menyebabkan masalah pada kinerja jalan yang sudah tersedia.

Cepatnya pertumbuhan suatu kota yang tidak terkendali mengakibatkan munculnya sebuah kegiatan yang beraneka ragam yang dapat berdampak pada salah satu gangguan lalu lintas [6][7]. Masalah pada kinerja jalan yang terjadi akan menyebabkan kemacetan jika masalahnya sudah terlampau parah dan bisa juga hanya terjadi tundaan saja jika masalah kinerja jalan tidak terlalu parah [8][9]. Terdapat beberapa hal yang mempengaruhi kinerja lalu lintas diantaranya adalah karakteristik lalu lintas, volume lalu lintas, hambatan samping, kecepatan arus bebas, kapasitas ruas jalan dan juga derajat kejenuhan[10][11].

Pertumbuhan lalu lintas normal merupakan peningkatan sebuah volume lalu lintas yang ada, yang disebabkan karena meningkatnya meningkatnya jumlah kendaraan yang digunakan dan juga karena perubahan dalam jumlah penggunaan kendaraan (kilometer) [12][13].

Derajat kejenuhan ialah rario arus lalu lintas terhadap kapasitas jalan, digunakan sebagai faktor kunci dalam penentuan tingkat pelayanan atau tingkat kinerja suatu segmen jalan [14].Semakin tinggi nilai derajat kejenuhan maka semakin tinggi kecepatan tempuh, hal itu menunjukkan semakin baiknya kinerja atau pelayanan lalu lintas.

(Limantara, Candra, and Mudjanarko, 2017) Pertambahan jumlah kendaraan yang tidak diimbangi dengan perkembangan prasarana akan menimbulkan konflik pada jalan khususnya pada persimpangan atau bundaran [15][16]. Seperti pada wilayah Kota Malang ini, pesatnya pertumbuhan kota mengakibatkan daya tarik kota ini semakin banyak didatangi oleh pengunjung dari luar wilayah Kota Malang itu sendiri.

Di depan pusat perbelanjaan hypermart tersebut sering terjadi kendaraan yang berhenti dipinggir jalan, meskipun jalan lumayan lebar dan juga searah namun karena pengendara yang terkadang berhenti di sekitar hypermart untuk antri masuk ke parkiran juga lumayan mengganggu, selain pengendara motor angkutan umum yang sering sekali berhenti dipinggir jalan depan hypermart untuk menunggu penumpang juga tidak jarang menyebabkan lajur lalu lintas semakin sempit. Adapun batasan masalah dalam penulisan ini:

(1) Pengamatan dilaksanakan hanya pada lalu lintas jalan sekitar pusat perbelanjaan hypermart Jl. Veteran, Penanggungan, Klojen, Malang. 
(2) Pengamatan terfokuskan hanya pada kinerja lalu lintas jalan sekitar pusat perbelanjaan hypermart Jl. Veteran, Penanggungan, Klojen, Malang saja.

(3) Pengamatan dilakukan hanya pada dua lokasi, yang pertama didepan pusat perbelanjaan hypermart dan yang kedua didepan Universitas Negeri Malang.

\section{METODE PENELITIAN}

\subsection{Lokasi Penelitian.}

Penelitian ini dilakukan di jalan sekitar hypermart Jl. Veteran, Penanggungan, Klojen, Malang.Lokasi pengamatan dibagi menjadi 2 lokasi, yang pertama berada didepan pusat perbelanjaan hypermart dan yang kedua berada diseberang jalan, tepatnya didepan Universitas Negeri Malang.

\subsection{Volume Kendaraan}

Volume lalu lintas kendaraan adalah jumlah kendaraan yang melalui suatu ruas jalan pada periode waktu tertentu [20]. Volume lalu lintas kendaraan dapat dirumuskan sebagai berikut ini.

$$
\mathrm{Q} s m p=(\operatorname{emp~MC~x~MC)~}+(\operatorname{emp} L V x \text { LV })+(\text { emp HVx HV })
$$

Dimana:

Q $\quad=$ Volume kendaraan bermotor $(\mathrm{smp} / \mathrm{jam})$

Emp MC = Nilai ekivalen mobil penumpang untuk sepeda motor

$\mathrm{MC}=$ Jumlah sepeda motor

Emp LV = Nilai ekivalen mobil penumpang untuk kendaraan ringan

$\mathrm{LV}=$ Jumlah kendaraan ringan

Emp HV = Nilai ekivalen mobil penumpang untuk kendaraan berat

$\mathrm{HV}=$ Jumlah kendaraan berat

\subsection{Derajat Kejenuhan}

Derajat Kejenuhan adalah rasio arus trhadap kapasitas, digunakan sebagai faktor utama dalam penentuan tingkat kinerja segmen jalan. Nilai DS menunjukkan apakah segmen jalan tersebut mempunyai masalah kapasitas atau tidak. Derajat kejenuhan dihitung dengan menggunakan arus dan kapasitas dinyatakan dalam smp/jam (MKJI, 1997) [14].

$L O S=\frac{Q}{C}$

Dimana : 
LOS $=$ Derajat Kejenuhan

$\mathrm{Q}=$ Arus Lalu Lintas

$\mathrm{C}=$ Kapasitas (smp/jam)

\subsection{Metode Yang Digunakan}

Metode penelitian adalah cara ilmiah yang digunakan untuk mendapatkan data dengan tujuan serta kegunaan tertentu [17][18]. Sedangkan yang dimaksud data primer ialah data yang diperoleh dari sumber pertama [19].

Dalam penulisan tugas akhir ini digunakan metode analisis deskriptif, yaitu observasi yang dilakukan langsung di lapangan yang bertujuan untuk mendapatkan data-data yang dibutuhkan.Selain menggunakan metode tersebut penulis juga mencari literature-literature untuk digunakan sebagai bahan penunjang teknik survey yang akan dilakukan serta pengolahan data nantinya. Selain itu penulis juga menggunakan data historyjumlah volume kendaraan5 tahun yang lalu pada wilayah tersebut yang diperoleh dari mahasiswa UM.

Selain menggunakan metode tersebut penulis juga melakukan persiapan-persiapan seperti: menentukan lokasi, menetukan siapa saja yang melakukan pengamatan, menentukan waktu pengamatan dilakukan, serta mencari informasi mengenai tempat yang akan dilakukan pengamatan.

\section{HASIL DAN PEMBAHASAN}

\subsection{Volume Kendaraan}

Ada beberapa jenis kendaraan, yaitu : Sepeda Motor (MC), Kendaraan Ringan (LV) dan juga Kendaraan Berat (HV)[20]. Data jumlah kendaraan kemudian dihitung dalam kendaraan/jam untuk setiap kendaraan dengan faktor koreksi masing-masing yaitu 0.2 untuk MC, 1 untuk LV dan 1.3 untuk HV. Untuk menghitung volume kendaraan yang terjadi dapat digunakan rumus:

$$
\mathrm{Q} s m p=(e m p \text { MC x MC })+(\operatorname{emp~LVx~LV})+(\text { emp HVx HV })
$$

Dimana:

Q $=$ Volume kendaraan bermotor $(\mathrm{smp} / \mathrm{jam})$

Emp MC = Nilai ekivalen mobil penumpang untuk sepeda motor

$\mathrm{MC}=$ Jumlah sepeda motor

Emp LV = Nilai ekivalen mobil penumpang untuk kendaraan ringan

$\mathrm{LV} \quad=$ Jumlah kendaraan ringan

Emp HV = Nilai ekivalen mobil penumpang untuk kendaraan berat

HV $=$ Jumlah kendaraan berat 
Volume kendaraan tertinggi pada tanggal 17 Juni 2019di lokasi pertama terjadi pada pukul 07.00-08.00.pada jam-jam tersebut banyak sekali kendaraan yang melintas di Jl. Veteranini dikarenakan. Volume kendaraan yang melintas pada pukul 07.00-08.00 sebanyak 3433 kendaraan sepeda motor (MC), 772 kendaraan ringan (LV) dan juga 8 kendaraan berat (HV).

Tabel 1. Volume Puncak Lalu Lintas Lokasi Pertama Terjadi pada pukul 07.00-08.00 (17 Juni 2019)

\begin{tabular}{|c|c|c|c|c|c|c|c|c|}
\hline \multirow{4}{*}{ Waktu } & \multicolumn{6}{|c|}{ Jenis Kendaraan } & \multirow{2}{*}{\multicolumn{2}{|c|}{ Volume Jam Puncak }} \\
\hline & \multicolumn{2}{|c|}{ MC } & \multicolumn{2}{|c|}{$\mathrm{LV}$} & \multicolumn{2}{|c|}{$\mathrm{HV}$} & & \\
\hline & \multirow{2}{*}{ kend/Jam } & smpjam & \multirow{2}{*}{ kend/jam } & smpjam & \multirow{2}{*}{ kendjam } & smpjam & \multirow{2}{*}{ kendjam } & \multirow{2}{*}{ smpjam } \\
\hline & & 0.2 & & 1 & & 1.3 & & \\
\hline (07.00-08.00 & 3433 & 686.6 & 772 & 772 & 8 & 10.4 & 4213 & 1469 \\
\hline
\end{tabular}

Sumber: Hasil Survey oleh penulis

Tabel 2. Volume Puncak Lalu Lintas Lokasi Kedua Terjadi Pada Pukul 07.00-08.00 (17 Juni 2019)

\begin{tabular}{|c|c|c|c|c|c|c|c|c|}
\hline \multirow{4}{*}{ Waktu } & \multicolumn{6}{|c|}{ Jenis Kendaraan } & \multirow{2}{*}{\multicolumn{2}{|c|}{ Volume Jam Puncak }} \\
\hline & \multicolumn{2}{|c|}{$\mathrm{MC}$} & \multicolumn{2}{|c|}{ LV } & \multicolumn{2}{|c|}{$\mathrm{HV}$} & & \\
\hline & \multirow{2}{*}{ kend/Jam } & smp/jam & \multirow{2}{*}{ kend/jam } & smp/jam & \multirow{2}{*}{ kend/jam- } & smp/jam & \multirow{2}{*}{ kend/jam } & \multirow{2}{*}{ smp/jam } \\
\hline & & 0.2 & & 1 & & 1.3 & & \\
\hline "07.00-08.00 & 2531 & 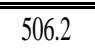 & 593 & ב593 & 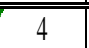 & ב5.2 & 3128 & 1104.4 \\
\hline
\end{tabular}

Sumber: Hasil Survey oleh penulis

\subsection{Kapasitas Ruas Jalan}

Kapasitas ruas jalan yang terdapat pada wilayah perkotaan dapat dihitung dengan menggunakan rumus[16]:

$$
\mathrm{C}=\operatorname{Co} \times \mathrm{FCw} \times \mathrm{FCsp} \times \mathrm{FCsf} \times \mathrm{FCcs}(2)
$$

Dimana :

$\mathrm{C} \quad=$ Kapasitas ruas jalan $(\mathrm{smp} / \mathrm{jam})$

Co $\quad=$ Kapasitas dasar $(\mathrm{smp} / \mathrm{jam})$

$\mathrm{FCw}=$ Faktor penyesuaian lebar jalur lalu lintas

FCsp $=$ Faktor penyesuaian pemisah arah

FCsf $=$ Faktor penyesuaian akibat hambatan samping

FCcs $=$ Faktor penyesuaian ukuran kota . 
Dari data penulis yang didapatkan dilapangan makadiperoleh hasil perhitungan sebagai berikut:

$\mathrm{C}($ Lokasi Pertama $)=\mathrm{C}_{\mathrm{O}} \times \mathrm{FC}_{\mathrm{W}} \times \mathrm{FC}_{\mathrm{SP}} \times \mathrm{FC}_{\mathrm{SF}} \times \mathrm{FC}_{\mathrm{cs}}$

$=6600 \times 0.92 \times 1.00 \times 0.90 \times 0.86=4699.73 \mathrm{smp} / \mathrm{jam}$

$\mathrm{C}($ Lokasi Kedua $)=\mathrm{C}_{\mathrm{O}} \mathrm{F} \mathrm{FC}_{\mathrm{W}} \times \mathrm{FC}_{\mathrm{SP}} \times \mathrm{FC}_{\mathrm{SF}} \times \mathrm{FC}_{\mathrm{cs}}$

$=6600 \times 0.92 \times 1.00 \times 0.90 \times 0.86=4699.73 \mathrm{smp} / \mathrm{jam}$

Tabel 3. Perhitungan Kapasitas Ruas Jalan Pada Lokasi Pertama (17 Juni 2019)

\begin{tabular}{|c|c|c|c|c|c|}
\hline Co & \multicolumn{4}{|c|}{ Faktor Penyesuaian } & C \\
\hline$($ smp/jam) & FC $_{\text {W }}$ & FCsP & FCsP & FCcs & (smp/jam) \\
\hline \hline 6600 & 0.92 & 1 & 0.90 & 0.86 & 4699.728 \\
\hline
\end{tabular}

Sumber: Hasil Survey oleh penulis

Tabel 4. Perhitungan Kapasitas Ruas Jalan pada Lokasi Kedua (17 Juni 2019)

\begin{tabular}{|c|c|c|c|c|c|}
\hline Co & \multicolumn{4}{|c|}{ Faktor Penyesuaian } & $\mathrm{C}$ \\
\hline (smp/jam) & $\mathrm{FC}_{\mathrm{W}}$ & FCsp & FCsF & FCcs & (smp/jam) \\
\hline 6600 & 0.92 & 1 & 0.9 & 0.86 & 4699.728 \\
\hline
\end{tabular}

Sumber: Hasil Survey oleh penulis

\subsection{Derajat Kejenuhan}

LOS (Level of Service) atau tingkat pelayanan jalan adalah salah satu metode yang

digunakan untuk menilai sebuah kinerja jalan atau lalu-lintas yang menjadi indicator dari kemacetan. Suatu jalan dikategorikan mengalami kemacetan apabila hasil perhitungan LOS nilainya mendekati 1.Level of Service (LOS) dapat diketahui dengan melalui perhitungan volume lalu-lintas dibagi dengan kapasitas jalan (V/C). Tingkat pelayanandapat dihitung dengan rumus[16] :

$$
L O S=\frac{Q}{C}
$$

Dimana nilai $\mathrm{Q}($ Lokasi Pertama $)=1464 \mathrm{smp} / \mathrm{jam}$

$\mathrm{Q}($ lokasi Kedua $)=1104.4 \mathrm{smp} / \mathrm{jam}$

$$
\mathrm{C}=4699.73 \mathrm{smp} / \mathrm{jam}
$$


Maka, LOS $($ Lokasi Pertama $)=\frac{1464}{4699.73}=0.31(B)$

Dan LOS $($ Lokasi Kedua $)=\frac{1104.4}{4699.73}=0.23(B)$

Tabel 5. Analisis Derajat Kejenuhan Pada Lokasi Pertama (17 Juni 2019)

\begin{tabular}{|c|c|c|c|}
\hline $\mathbf{Q}$ & $\mathbf{C}$ & $\mathbf{D}$ & \multirow{2}{*}{ Pelayanan Jalan } \\
\hline \hline (smp/jam) & (smp/jam) & $(\mathbf{s m p} / \mathbf{j a m})$ & \\
\hline \hline 1469 & 4699.728 & 0.31 & $\mathrm{~B}$ \\
\hline
\end{tabular}

Sumber: Hasil Survey oleh penulis

Tabel 6. Analisis Derajat Kejenuhan Pada Lokasi Kedua (17 Juni 2019)

\begin{tabular}{|c|c|c|c|}
\hline $\mathbf{Q}$ & $\mathbf{C}$ & $\mathbf{D}$ & \multirow{2}{*}{ Pelayanan Jalan } \\
\hline \hline (smp/jam) & $(\mathbf{s m p} /$ jam) & $(\mathbf{s m p} / \mathbf{j a m})$ & \\
\hline \hline 1104.4 & 4699.728 & 0.23 & $\mathrm{~B}$ \\
\hline
\end{tabular}

Sumber: Hasil Survey oleh penulis

\section{KESIMPULAN}

1. Volume puncak lalu lintas sekitar hypermart Jl. Veteran, Penanggungan, Klojen, Malang pada lokasi pertama berada pada jam 07.00-08.00 dengan volume lalu-lintas $1469 \mathrm{smp} / \mathrm{jam}$ sedangkan pada lokasi kedua volume lalu-lintas terpadat juga dialami pada jam yang sama dengan volume lalu-lintas $1104.4 \mathrm{smp} / \mathrm{jam}$.

2. Kapasitas ruas jalan pada lokasi pertama dan kedua sama-sama berkapasitas sebesar $4699.73 \mathrm{smp} / \mathrm{jam}$.

3. Untuk nilai analisi kinerja lalu-lintas pada lokasi penelitian, derajat kejenuhan pada lokasi pertama sebesar $0.31 \mathrm{smp} / \mathrm{jam}$ sedangkan pada lokasi kedua sebesar $0.23 \mathrm{smp} / \mathrm{jam}$ yang artinya dari kedua niai tersebut termasuk kedalam tingkat pelayan lalu-lintas kelas B.

4. Evaluasi untuk kinerja lalu-lintas sekitar hypermart Jl. Veteran, Penanggungan, Klojen, Malang yang terjadi di lapangan:

- Sering terdapat kendaraan bermotor dan juga kendaraan umum yang berhenti di Jl.Veteran sekitar hypermart yang menyebabkan pengguna jalan merasa kurang nyaman pada saat berkendara.

- Rambu-rambu lalu-lintas pada lokasi pengamatan pertama yang masih kurang. 
- Perlu perbaikan jalan ketika masuk kedalam pusat perbelanjaan hypermart, jalan untuk masuk ke parkiran kurang bagus sehingga kendaraan yang masuk ke hypermart mengganggu kecepatan pengendara yang lain.

- Meningkatkan ketertiban area parkir kawasan hypermart

- Penataan PKL pada area depan sekolahan.

\section{SARAN}

Perlu diadakan tindak lanjut untuk ketertiban parkir dikawasan hypermart. Perlu diadakan penelitian lebih lanjut mengenai ketersediaan tempat parkir disekitar lokasi sekolah SMP dan juga SMA yang berada disebelah Universitas Negeri Malang supaya orangtua siswa yang menjemput anaknya sekolah tidak berada dipinggir jalan veteran, penanggungan, klojen, malang. Kekurangan yang terdapat pada penulisan ini dapat menjadi bahan perbaikan pada penelitian-penelitian selanjutnya.

\section{UCAPAN TERIMAKASIH}

Dalam penyusunan artikel ini, penulis ucapkan terimakasih kepada dosen pembimbing dan Universitas Kadiri. Penulis berharap agar artikel ini dapat bermanfaat bagi pembaca.

\section{DAFTAR PUSTAKA}

[1] A. S. Jiwangga, "Analisis Faktor Pengaruh..., Argya Sukma Jiwangga, Fak. Teknik UMP 2017 4," vol. 3, pp. 4-14, 2017.

[2] F. A. Lestari and Y. Apriyani, "ANALISIS DAMPAK LALU LINTAS AKIBAT ADANYA PUSAT PERBELANJAAN DIKAWASAN PASAR PAGI PANGKALPINANG TERHADAP KINERJA RUAS JALAN,” J. Fropil, vol. 2, no. 1, pp. 32-44, 2014.

[3] R. Rahman, “Analisa Dampak Lalu Lintas (Studi Kasus: Studi Kemacetan di Jalan Ngagel Madya Surabaya)," SMARTek, vol. 8, pp. 317-332, 2010.

[4] N. Hidayah, "Disiplin Lalu Lintas Pengendara Sepeda Motor Roda Dua di Kecamatan Tampan Pekanbaru," J. FISIP, vol. 2, no. 1, pp. 1-15, 2015.

[5] A. I. Candra, "STUDI KASUS STABILITAS STRUKTUR TANAH LEMPUNG PADA JALAN TOTOK KEROT KEDIRI MENGGUNAKAN LIMBAH KERTAS," UKaRsT, 2018, doi: 10.30737/ukarst.v2i2.255.

[6] E. N. Julianto, "Hubungan Antara Kecepatan, Volume Dan Kepadatan Lalu Lintas Ruas Jalan Siliwangi Semarang,” J. Tek. Sipil dan Perenc., vol. 12, no. 2, pp. 151-160, 2010.

[7] S. J. Legowo and D. Anggoro, "Studi Evaluasi Dampak Lalu Lintas Akibat Pembangunan 
Stasiun Pengisian Bahan Bakar Umum ( Spbu ) Manahan,” pp. 601-609, 2014.

[8] A. I. Candra, A. Yusuf, and A. R. F, "Studi Analisis Daya Dukung Pondasi Tiang Pada Pembangunan Gedung Lp3M Universitas Kadiri,” J. CIVILA, vol. 3, no. 2, p. 166, 2018, doi: $10.30736 /$ cvl.v3i2.259.

[9] S. Awiyaningsih, H. Moetriono, and D. T. Sipil, "ANALISIS DAMPAK LALU LINTAS AKIBAT PEMBANGUNAN MALL LAGOON AVENUE SUNGKONO TERHADAP KINERJA SIMPANG DI JL MAYJEND SUNGKONO - HR MUHAMMAD SURABAYA,” Tek. Eng. Sains J., vol. 2, no. 2, pp. 131-134, 2018.

[10] Direktorat Jendral Bina Marga, "R s 2010-2014,” 2014.

[11] M. Atho 'ur Rohman, D. Kartikasari, K. Kunci, and : Kemacetan, "ANALISA KEMACETAN LALU LINTAS PADA PASAR TRADISIONAL DI RUAS JALAN SEKARAN-MADURAN," J. CIVILA, vol. 1, no. 2, pp. 1-6, 2016.

[12] A. H. Hasim, "ahun Mendatang Dengan PROGRAM ANAKinerja Ruas Jalan Sultan Alauddin untuk 10 TLISIS LALU LINTAS KAJI \& POWER,” no. December, 2017, doi: 10.13140/RG.2.2.21391.48800.

[13] S. Awiyaningsih, H. Moetriono, and S. W. Mudjanarko, "ANALISIS DAMPAK LALU LINTAS PEMBANGUNAN MALL LAGOON AVENUE SUNGKONO TERHADAP KINERJA SIMPANG DI JALAN MAYJEND SUNGKONO - HR MUHAMMAD SURABAYA,” Tek. Eng. Sains J., vol. 2, no. 2, pp. 131-134, 2018.

[14] Anonim, Manual Kapasitas Jalan Indonesia. Jakarta, 1997.

[15] A. D. Limantara, A. I. Candra, and S. W. Mudjanarko, "Manajemen Data Lalu Lintas Kendaraan Berbasis Sistem Internet Cerdas Ujicoba Implementasi Di Laboratorium Universitas Kadiri,” Pros. Semnastek, 2017.

[16] R. H. Lalenoh, T. K. Sendow, and F. Jansen, “Analisa Kapasitas Ruas Jalan Sam Ratulangi Dengan Metode Mkji 1997 Dan Pkji 2014,” J. Sipil Statik, vol. 3, no. 11, pp. 737-746, 2015.

[17] G. R. Gumilar, "Guruh Rahmat Gumilar, 2013 Kontribusi Pelatihan Kewirausahaan Terhadap Motivasi Berwirausaha Bagi Peserta Pelatihan Persiapan Purna Bakti Bakti Di Lembega LP2ES Bandung Universitas Pendidikan Indonesia | repository.upi.edu | perpustakaan.upi.edu," p. 34, 2013.

[18] E. Kusnandar, “Manual Kapasitas Jalan Indonesia 1997," J. Jalan dan Jemb., vol. 26, no. 2, pp. 1-11, 2009.

[19] A. R. L. Francisco, "Journal of Chemical Information and Modeling," J. Chem. Inf. Model., vol. 53, no. 9, pp. 1689-1699, 2013, doi: 10.1017/CBO9781107415324.004.

[20] J. Patunrangi, “ANALISA KINERJA JALAN PENDEKAT PADA BEBERAPA 
JEMBATAN DI KOTA PALU (Studi kasus: Jembatan Palu I, II, III dan IV),” vol. 1, pp. 42-56, 2011. 